\title{
PENGARUH METODE TOKEN ECONOMY TERHADAP \\ MOTIVASI BELAJAR MATEMATIKA PESERTA DIDIK \\ KELAS III B MI MA'ARIF GIRILOYO 2
}

\begin{tabular}{c} 
Dina Ayu Fadzila \\
SD Salatiga 6 \\
Email: fadziladinaayu@ gmail.com \\
\hline
\end{tabular}

\begin{abstract}
ABSTRAK
Penelitian bertujuan untuk mengetahui pengaruh metode token economy terhadap motivasi belajar matematika dan sumbangan pengaruh metode token economy terhadap motivasi belajar matematika peserta didik kelas III B MI Ma'arif Giriloyo 2. Metode penelitian yang digunakan adalah eksperimen semu (quasi experiment) dengan metode pengumpulan data menggunakan observasi, angket dan dokumentasi. Data dianalisis menggunakan analisis regresi linier sederhana. Hasil penelitian menunjukkan: 1) terdapat pengaruh antara penggunaan metode token economy terhadap motivasi belajar matematika yang ditunjukkan dengan nilai $\mathrm{P}$ sebesar 0,036 dan 0,001 atau $\mathrm{P}<0,05$. Artinya, $\mathrm{H}_{0}$ ditolak dan $\mathrm{H}_{1}$ diterima. Pengaruh positif ini menunjukkan nilai token economy meningkat maka motivasi belajar matematika meningkat. Sumbangan pengaruh metode token economy terhadap motivasi belajar peserta didik kelas III B MI Ma'arif Giriloyo 2 sebesar 0,484 atau $48,4 \%$ ditunjukkan dalam kolom $R$ square $\left(\mathrm{R}^{2}\right)$, sedangkan sisanya sebesar $51,6 \%$ disebabkan oleh faktor lain yang tidak disertakan dalam penelitian ini.
\end{abstract}

\section{Kata kunci: Metode Token Economy, Motivasi Belajar Matematika, Regresi Linier Sederhana.}

\section{ABSTRACT}

The study aimed to determine the effect of the token economy method on motivation to learn mathematics and the contribution of the effect of the token economy method on the motivation to learn mathematics in grade 3 students of MI Ma'arif Giriloyo 2. The research method used was quasi-experimental with data collection 
methods using observation, questionnaire and documentation. Data were analyzed using simple linear regression analysis. The results showed: 1) there was an influence between the use of the token economy method on mathematics learning motivation as indicated by a $P$ value of 0.036 and 0.001 or $P<0.05$. That is, $H O$ is rejected and $\mathrm{HI}$ is accepted. This positive influence shows the value of the token economy increases, the motivation to learn mathematics increases. The contribution of the effect of the token economy method on the learning motivation of class III B MI Ma'arif Giriloyo 2 students is 0.484 or $48.4 \%$ indicated in the R square (R2) column, while the remaining $51.6 \%$ is caused by other factors not included in the this research.

\section{Keywords: Token Economy Method, Mathematics Learning Motivation, Simple Linear Regression.}

\section{A. PENDAHULUAN}

Matematika merupakan ilmu universal yang mempunyai peran penting dalam berbagai disiplin ilmu serta berperan besar dalam perkembangan teknologi informasi dan komunikasi yang kian pesat. Bahkan, penguasaan teknologi yang kian pesat memerlukan penguasaan matematika yang kuat sejak dini. ${ }^{1}$ Hakikat matematika adalah ilmu tentang pola dan hubungan, sebab dalam matematika sering dicari keseragaman seperti keterurutan, dan keterkaitan pola dari sekumpulan konsep-konsep tertentu atau model-model yang merupakan representasinya, sehingga dapat dibuat generalisasinya untuk selanjutnya dibuktikan kebenarannya secara deduktif. ${ }^{2}$

Heruman menyebutkan bahwa pembelajaran matematika di Sekolah Dasar (SD)/Madrasah Ibtidaiyah (MI) memiliki desain kurikulum yang dibagi menjadi tiga kelompok besar, yaitu

\footnotetext{
1 Ibrahim and Suparni, Pembelajaran Matematika Teori Dan Aplikasinya (Yogyakarta: Suka Press, 2012), hlm. 35.

${ }^{2}$ Ibrahim and Suparni, hlm. 5.
} 
penanaman konsep dasar (penanaman konsep), pemahaman konsep, dan pembinaan konsep. Sehingga pembelajaran matematika di SD/MI memiliki tujuan akhir agar peserta didik terampil dalam menggunakan berbagai konsep matematika dalam kehidupan seharihari. $^{3}$

Tujuan belajar tidaklah mudah didapat tanpa adanya dukungan motivasi dari peserta didik. Motivasi menjadi kebutuhan dalam belajar untuk mencapai tujuan yang diharapkan yaitu hasil belajar yang diharapkan. Dalam kegiatan belajar, motivasi dapat dikatakan sebagai keseluruhan daya penggerak di dalam diri peserta didik yang menimbulkan kegiatan belajar, yang menjamin kelangsungan dari kegiatan belajar dan yang memberikan arah pada kegiatan belajar, sehingga tujuan yang dikehendaki oleh subjek belajar itu dapat tercapai. $^{4}$

Eva Latipah menyebutkan bahwa motivasi memang sangat penting untuk meningkatkan prestasi belajar. Namun perlu diingat, motivasi menjadi kurang berarti tanpa disertai dengan penggunaan metode-metode yang sesuai ketika pembelajaran berlangsung. ${ }^{5}$ Pada masa awal sekolah dasar, para peserta didik sering kali tampak antusias dan bersemangat mempelajari hal-hal baru di sekolah. Namun ketika mereka menginjak kelas 3 dan 9, motivasi intrinsik untuk belajar dan menguasai materi pelajaran sekolah menurun.

\footnotetext{
${ }^{3}$ Heruman, Model Pembelajaran Matematika Di Sekolah Dasar (Bandung: PT. Remaja Rosdakarya, 2013), hlm. 2.

${ }^{4}$ Noer Rohmah, Psikologi Pendidikan (Yogyakarta: TERAS, 2012), hlm. 241.

5 Eva Latipah, Pengantar Psikologi Pendidikan (Yogyakarta: Insan Madani, 2012), hlm. 160.
} 
Maka dari itu pentingnya peran dari motivasi ekstrinsik untuk mencapai tujuan belajar yang diharapkan. ${ }^{6}$

Peran guru sangat diperlukan sebagai motivator yang baik bagi peserta didik. Guru dituntut untuk terus belajar mengenai cara-cara membangkitkan motivasi. Maka dari itu perlu adanya pemahaman yang baik mengenai hal-hal yang dapat mendorong dan menggerakkan peserta didik. Dengan demikian, tugas guru harus mampu mendorong para peserta didik agar tumbuh motivasi untuk mencapai tujuan pembelajaran yang diharapkan. ${ }^{7}$

Metode token economy merupakan bagian dari modifikasi perilaku yang merupakan segala tindakan yang bertujuan mengubah perilaku atau usaha untuk menerapkan prinsip-prinsip proses belajar maupun prinsip-prinsip psikologi hasil eksperimen lain pada perilaku manusia. ${ }^{8}$ Modifikasi perilaku ini dapat berupa peningkatan, pemeliharaan, pengurangan, dan penghilang dan perkembangan atau perluasan. ${ }^{9}$ Teori pembiasaan perilaku ini disebut dengan operant conditioning, teori ini diciptakan oleh BF. Skinner. Operant Conditioning yaitu respon yang timbul dan berkembangnya diikuti oleh stimulan tertentu. Stimulan yang demikian itu disebut reinforcing stimuli atau reinforcer, karena perangsang itu memperkuat respon yang telah dilakukan oleh organisme. Sehingga memperkuat suatu tingkah laku tertentu yang telah dilakukan. Seorang anak yang belajar telah melakukan

\footnotetext{
${ }^{6}$ Latipah, hlm. 176.

${ }^{7}$ Oemar Malik, Psikologi Belajar \& Mengajar (Bandung: Sinar Baru Algesindo, 2007), hlm. 176.

${ }^{8}$ Sutarlinah Sukaji, Modifikasi Perilaku: Penerapan Sehari-Hari Dan Profesional (Yogyakarta: Liberty, 1983), hlm. 1.

${ }^{9}$ Sukaji, hlm. 10.
} 
perbuatan lalu mendapatkan hadiah, maka ia akan menjadi lebih giat belajar (responnya menjadi lebih intensif/kuat). ${ }^{10}$ Metode juga merupakan operant conditioning di mana menggunakan hadiah sebagai reinforcer atas tindakan yang muncul. Token economy sering disebut tabungan kepingan, di mana peserta didik yang telah mendapatkan kepingan dengan jumlah tertentu maka dapat ditukarkan dengan hadiah sesuai dengan kesepakatan yang telah dibuat. Kepingan didapatkan dengan cara melakukan suatu tindakan yang telah disetujui/dibuat sebelumnya. ${ }^{11}$

Edi Purwanta mengungkapkan bahwa tabungan kepingan (token) adalah salah satu teknik modifikasi perilaku dengan cara pemberian satu kepingan (atau satu tanda, isyarat) sesegera mungkin setelah perilaku sasaran muncul. Kepingan-kepingan ini nantinya dapat ditukar dengan benda atau aktivitas pengukuh lain yang seringkali disebut pengukuh idaman. ${ }^{12}$ Edi Purwanta mengungkapkan pelaksanaan tabungan kepingan dibagi dalam 3 tahap, yaitu tahap persiapan, tahap pelaksanaan, dan tahap evaluasi. $^{13}$

Penerapan metode token economy dapat meningkatkan motivasi belajar peserta didik. Karena untuk mendapatkan kepingan berupa bintang, peserta didik harus belajar lebih giat, maupun mengerjakan tugas-tugas dengan baik. Tidak hanya itu ketika diberi pertanyaan oleh guru dan peserta didik mampu menjawab dengan baik, maka ia

\footnotetext{
${ }^{10}$ Ngalim Purwanto, Psikologi Pendidikan (Bandung: PT. Remaja Rosdakarya, 2007), hlm. 95-96.

${ }^{11}$ Edi Purwanta, Modifikasi Perilaku (Yogyakarta: Pustaka Pelajar, 2015), hlm. 148-149.

12 Purwanta, hlm. 174.

${ }^{13}$ Purwanta, hlm. 178.
} 
juga berhak mendapatkan kepingan. Selain itu ketika ada peserta didik yang tertib dan memperhatikan guru saat pembelajaran maka juga berhak mendapatkan kepingan atau membantu pemahaman teman yang kurang terhadap suatu masalah dalam pembelajaran maka ia juga berhak mendapatkannya. Metode token economy selain meningkatkan motivasi belajar peserta didik juga berguna untuk meningkatkan perilaku positif peserta didik yang diharapkan dalam pembelajaran. Prinsip-prinsip metode token economy meliputi: 1) lingkungan dapat dikontrol; 2) sasaran perilaku harus spesifik; 3) tujuan terukur; 4) bentuk atau jenis benda sebagai kepingan jelas; 5) kepingan sebagai hadiah; 6) sesuai dengan perilaku; 7) mempunyai makna lebih sebagai pengukuh. ${ }^{14}$

Dalam kegiatan belajar, motivasi dapat dikatakan sebagai keseluruhan daya penggerak di dalam diri peserta didik yang menimbulkan kegiatan belajar, yang menjamin kelangsungan dari kegiatan belajar dan memberikan arah pada kegiatan belajar, sehingga tujuan yang dikehendaki oleh subjek belajar itu dapat tercapai. Dikatakan "keseluruhan", karena pada umumnya ada beberapa motif yang bersama-sama menggerakkan peserta didik untuk belajar. Atau dengan kata lain motivasi belajar adalah daya penggerak dari dalam diri individu untuk melakukan kegiatan belajar untuk menambah pengetahuan dan keterampilan serta pengalaman. Motivasi ini tumbuh karena ada keinginan untuk bisa mengetahui dan memahami sesuatu dan mendorong serta mengarahkan minat

\footnotetext{
${ }^{14}$ Purwanta, hlm. 151-152.
} 
belajar peserta didik sehingga sungguh-sungguh untuk belajar dan termotivasi untuk mencapai prestasi. ${ }^{15}$

Peranan motivasi yang khas adalah dalam hal penumbuh gairah, merasa senang dan semangat untuk belajar, peserta didik yang memiliki motivasi kuat, akan mempunyai banyak energi untuk melakukan kegiatan belajar. Seorang peserta didik yang mempunyai intelegensi yang cukup tinggi, boleh jadi gagal karena kekurangan motivasi. Hasil belajar akan lebih optimal kalau ada motivasi yang tepat. $^{16}$

Secara umum, dikatakan bahwa tujuan motivasi adalah untuk menggerakkan atau menggugah seseorang agar timbul keinginan dan kemauannya untuk melakukan sesuatu sehingga dapat memperoleh hasil atau mencapai tujuan tertentu. Bagi seorang guru, tujuan motivasi adalah untuk menggerakkan atau memacu para peserta didik agar timbul keinginan dan kemauannya untuk meningkatkan prestasi belajarnya sehingga tercapai tujuan pendidikan sesuai dengan yang diharapkan dan ditetapkan. ${ }^{17}$

Motivasi ekstrinsik adalah motivasi melibatkan diri dalam sebuah aktivitas sebagai suatu cara mencapai sebuah tujuan. Individu-individu yang termotivasi secara ekstrinsik mengerjakan tugas-tugas karena mereka meyakini bahwa partisipasi tersebut akan menyebabkan berbagai konsekuensi yang diinginkan, seperti

\footnotetext{
15 Purwanta, hlm. 240-241.

${ }^{16}$ Purwanta, hlm. 243.

${ }^{17}$ Purwanto, Psikologi Pendidikan..., hlm. 73.
} 
mendapat hadiah, menerima pujian dari guru, atau terhindar dari hukuman. ${ }^{18}$

Dalam proses pembelajaran dengan teori ini, dapat diperkuat tingkah laku baik yang telah ditunjukkan peserta didik; dan sebaliknya memberikan hukuman bagi peserta didik yang menunjukkan kesalahan dalam proses pembelajaran. Dengan harapan, agar memberi penguatan terhadap perilaku baiknya itu, peserta didik akan mengulangi kembali perilaku baik itu. Sebaliknya, dengan diberi hukuman peserta didik diharapkan dapat meminimalisir atau bahkan meninggalkan perilaku yang tidak diharapkan terjadi dalam proses pembelajaran. ${ }^{19}$

Penting untuk diperhatikan bahwa, agar cara-cara yang digunakan untuk modifikasi perilaku tetap mempertimbangkan harkat dan martabat manusia yang harus selalu diakui dan dihormati, cara-cara tersebut ditempuh dengan "gaya" yang manusiawi pula. ${ }^{20}$ Hamzah B. Uno mengidentifikasi beberapa indikator motivasi belajar, antara lain: ${ }^{21}$ 1) Adanya hasrat dan keinginan berhasil; 2) Adanya dorongan dan kebutuhan dalam belajar; 3) Adanya harapan dan cita-cita masa depan; 4) Adanya penghargaan dalam belajar; 5) Adanya kegiatan yang menarik dalam belajar; 6) Adanya lingkungan belajar yang kondusif.

Berdasarkan observasi di MI Ma'arif Giriloyo 2 di kelas III B, khususnya dalam pembelajaran matematika, terdapat berbagai

18 Dale H. Schunk, Paul R. Pintrich, and Judith L. Meece, Motivasi Dalam Pendidikan : Teori, Penelitian Dan Aplikasi (Jakarta: Indeks, 2012), hlm. 357.

${ }^{19}$ Schunk, Pintrich, and Meece, hlm. 159-160.

${ }^{20}$ Schunk, Pintrich, and Meece, hlm. 160.

${ }^{21}$ Hamzah B. Uno, Teori Motivasi \& Pengukurannya (Jakarta: Bumi Aksara, 2008), hlm. 23. 
permasalahan yang ditemukan. Seperti adanya peserta didik yang sibuk dengan dirinya sendiri entah itu bermain sendiri saat guru sedang menerangkan maupun ketika guru memberikan instruksi untuk mengerjakan tugas-tugas yang diberikan, juga adanya peserta didik yang berbicara dengan temannya pada kegiatan tersebut. Selain itu terdapat peserta didik yang pasif dan acuh dalam mengikuti belajar, seperti tidak adanya dorongan kuat akan kebutuhan belajar. Berdasarkan pengamatan peneliti pula, metode yang digunakan dalam pembelajaran matematika kurang bervariasi (teacher centered) sehingga terkesan monoton dan menyebabkan motivasi belajar peserta didik kurang dilihat dengan mengabaikan perintah guru, bermain sendiri ketika proses pembelajaran, ada juga sebagian peserta didik yang tertidur di kelas, dan pengerjaan tugas yang tidak selesai. Selain itu di MI Maarif Giriloyo 2 sudah menerapkan sistem reward berbintang. Namun dalam praktik pelaksanaannya, tidak sesuai dengan teori yang ada selain itu praktik yang tidak fokus dalam pembelajaran matematika, sebab digunakan oleh guru kelas. Sedangkan matematika diajarkan oleh guru khusus matematika. ${ }^{22}$ Maka dari itu, peneliti ingin mencoba meneliti metode token economy diaplikasikan secara intens dalam pembelajaran matematika dengan tujuan mampu menumbuhkan perilaku positif dalam belajar. Sehingga meningkatkan motivasi belajar peserta didik yang berakibat terlaksananya tujuan pembelajaran yang diharapkan. Adapun tujuan penelitian ini adalah 1) Untuk mengetahui pengaruh metode token economy terhadap motivasi belajar matematika peserta

22 Observasi Proses Pembelajaran Mata Pelajaran Matematika Semester Ganjil Kelas III B di MI Ma'arif Giriloyo 2 pada tanggal 23 dan 25 Oktober 2017 
didik kelas III B MI Ma'arif Giriloyo .2) Untuk mengetahui seberapa besar sumbangan (kontribusi) metode token economy terhadap motivasi belajar matematika peserta didik kelas III B MI Ma'arif Giriloyo 2.

\section{B. METODE PENELITIAN}

Penelitian ini termasuk ke dalam jenis penelitian Quasi Experiment atau kuasi eksperimen dengan desain penelitian ini adalah Time-Series Design berulang (Repeated Treatment Design). Variabel bebas penelitian ini yaitu metode token economy dan variabel terikatnya motivasi belajar peserta didik. Instrumen pengumpul data yang digunakan adalah lembar observasi dan angket yang behavior checklist. Instrumen yang digunakan dalam penelitian terlebih dahulu melalui tahap validasi konstruk dan validasi empiris.

Data yang diperoleh kemudian dianalisis menggunakan Uji normalitas dilakukan untuk memeriksa apakah sampel berdistribusi normal (dalam hal ini adalah sampel jenuh). Bila data sampel berdistribusi normal maka pengolahan datanya dapat menggunakan statistika parametrik dan hasil pengolahan data atas sampel dapat digeneralisasikan kepada populasi. ${ }^{23}$ Pengujian statistika yang digunakan ialah uji kolmogrov-smirnov dalam software SPSS 23. Selanjutnya dilakukan Uji Linearitas Data untuk mengetahui apakah garis regresi antara " $\mathrm{X}$ " dan "Y" membentuk garis linear atau tidak. Kalau tidak linear maka analisis regresi tidak dapat dilanjutkan. ${ }^{24} \mathrm{Uji}$ linieritas ini dalam pelaksanaannya menggunakan analisis Anava.

\footnotetext{
${ }^{23}$ Sugiyono, Statistika Untuk Penelitian (Bandung: Alfabeta, 2014), hlm. 156.

${ }^{24}$ Sugiyono, Statistika Untuk Penelitian (Bandung: Alfabeta, 2014), hlm. 265.
} 
Kaidah yang digunakan adalah apabila $\mathrm{p}>0,05$ maka hubungan antara kedua variabel dinyatakan linier. Apabila $\mathrm{p}<0,05$ maka hubungan antara kedua variabel dinyatakan tidak linier. ${ }^{25}$

Uji hipotesis menggunakan regresi linear untuk mengetahui pengaruh pengaruh satu variabel bebas (independent) terhadap satu variabel tak bebas (dependent). ${ }^{26}$ Hasil data yang dianalisis dapat dilihat di kolom Sig. Apabila nilai Sig. $<0.05$, maka $\mathrm{H}_{0}$ ditolak dan $\mathrm{H}_{1}$ diterima. $^{27}$ Pengujian hipotesis dalam penelitian ini dapat dirumuskan sebagai berikut:

$\mathrm{H}_{0}$ : Tidak terdapat pengaruh penggunaan metode token economy terhadap motivasi belajar peserta didik.

$\mathrm{H}_{1}$ : Terdapat pengaruh metode token economy terhadap motivasi belajar peserta didik.

Untuk mengetahui sumbangan variabel yang diberikan. Dalam hal ini metode token economy terhadap motivasi belajar. Data dapat hasil analisis dapat dilihat pada analisis output kedua pada analisis regresi SPSS 23. Koefisien determinasi $\left(\mathrm{R}^{2}\right)$ bisa dilihat melalui kolom $R$ Square. ${ }^{28}$

\section{HASIL PENELITIAN DAN PEMBAHASAN}

Pengambilan data penelitian dilaksanakan pada bulan Januari 2018 sampai dengan Februari 2018 di MI Ma'arif Giriloyo

\footnotetext{
${ }^{25}$ Burhan Nurgiyantoro, Gunawan, and Marzuki, Statistik Terapan (Yogyakarta: Gadjah Mada University Press, 2015), hlm. 365.

${ }^{26}$ Sofyan Siregar, Statistika Terapan Untuk Perguruan Tinggi (Jakarta: Kencana, 2015), hlm. 220.

${ }^{27}$ Kadir, Statistika Terapan: Konsep, Contoh Dan Analisis Data Dengan Program SPSS/Lisrel Dalam Penelitian (Jakarta: Rajawali Pers, 2016), hlm. 186.

${ }^{28}$ Kadir, hlm. 187.
} 
2, Wukirsari, Imogiri, Bantul, Yogyakarta. Pelaksanaan penelitian dilaksanakan pada semester genap tahun ajaran 2017/2018. Objek penelitian yang diambil adalah peserta didik kelas III B. Pada penelitian ini hanya menggunakan satu kelas eksperimen dan tidak menggunakan kelas kontrol. Kelas eksperimen terdiri atas 20 peserta didik. Peserta didik laki-laki terdiri atas 9 anak dan perempuan terdiri atas 11 anak. Penelitian dilakukan dalam pembelajaran matematika materi unsur dan sifat bangun datar sederhana. Observasi dilakukan sebanyak tiga kali. Adapun deskripsi hasil observasi metode token economy dapat dilihat pada tabel 1 .

Tabel 1. Deskripsi Data Observasi

\begin{tabular}{lc}
\hline \multicolumn{1}{c}{ Data Statistik } & Kelas Eksperimen \\
\hline Mean (rata-rata) & 14,05 \\
\hline Median & 14,00 \\
\hline Mode & 15 \\
\hline SD & 0,999 \\
\hline Nilai Terendah & 12 \\
\hline Nilai Tertinggi & 15 \\
\hline
\end{tabular}

Dari hasil angket untuk mengetahui motivasi belajar siswa, didapatkan jawaban responden pada tabel 2.

Tabel 2. Diskripsi Data Angket

\begin{tabular}{lc}
\hline \multicolumn{1}{c}{ Data Statistik } & Kelas Eksperimen \\
\hline Mean (rata-rata) & 43,35 \\
\hline Median & 44,50 \\
\hline Mode & 45 \\
\hline SD & 2,852 \\
\hline Nilai Terendah & 33 \\
\hline Nilai Tertinggi & 45 \\
\hline
\end{tabular}


Instrumen angket dikatakan valid apabila nilai $\mathrm{r}$ minimum 0.3, maka bila nilai hasil output olah data dalam tabel Corrected Item-Total Correlation lebih besar dari 0.3 maka instrumen valid. Berdasarkan perhitungan dengan SPSS 23. berikut hasil validitas yang diperoleh.

Tabel 3. Hasil Output Validitas Instrumen

\begin{tabular}{|c|c|c|}
\hline No Item & $\begin{array}{c}\text { Corrected Item-Total } \\
\text { Correlation }\end{array}$ & Keterangan \\
\hline 1 & 0.696 & Valid \\
\hline 2 & 0.124 & Tidak valid \\
\hline 3 & -.149 & Tidak valid \\
\hline 4 & 0.614 & Valid \\
\hline 5 & 0.427 & Valid \\
\hline 6 & 0.146 & Tidak valid \\
\hline 7 & 0.427 & Valid \\
\hline 8 & 0.427 & Valid \\
\hline 9 & 0.046 & Tidak valid \\
\hline 10 & 0.551 & Valid \\
\hline 11 & 0.131 & Tidak valid \\
\hline 12 & 0.363 & Valid \\
\hline 13 & 0.100 & Tidak valid \\
\hline 14 & 0.427 & Valid \\
\hline 15 & -.107 & Tidak valid \\
\hline 16 & 0.427 & Valid \\
\hline 17 & 0.488 & Valid \\
\hline 18 & 0.447 & Valid \\
\hline 19 & 0.363 & Valid \\
\hline 20 & 0.046 & Tidak valid \\
\hline 21 & 0.560 & Valid \\
\hline 22 & 0.644 & Valid \\
\hline 23 & 0.247 & Tidak valid \\
\hline 24 & -.039 & Tidak valid \\
\hline 25 & 0.366 & Valid \\
\hline
\end{tabular}

Reliabilitas angket menggunakan uji dengan teknik Alpha Cronbach. Instrumen dikatakan reliabel apabila memenuhi nilai 
kriteria $r>0,6$. Berikut hasil output data melalui pengolahan SPSS 23 mengenai reliabilitas instrumen.

Tabel 4. Hasil Output Reliabilitas Instrumen

\begin{tabular}{ll}
\hline Cronbach's Alpha & N of Items \\
\hline .779 & 25 \\
\hline
\end{tabular}

Berdasarkan perolehan output olah data dalam Tabel 4, diketahui nilai Cronbach's Alpha yaitu 0,779. Sehingga dapat disimpulkan bahwa instrumen reliabel.

Uji prasyarat normalitas menggunakan teknik uji Kolmogorov-Smirnov dengan alat bantu SPSS 23. Syarat data diterima berdistribusi normal bila nilai taraf Sig. tabel lebih dari 0,05 (P > $5 \%$ ). Tabel 5 adalah hasil uji normalitas data observasi token economy maupun angket motivasi belajar matematika dalam penelitian ini.

Pada Tabel 5 tersebut diketahui nilai Sig. (2-tailed) adalah 0.240 untuk data metode token economy dan 0.084 untuk data motivasi belajar matematika. Hal ini menunjukkan bahwa keduanya berdistribusi normal karena nilainya lebih dari 0.05 .

Pengujian linearitas menggunakan SPSS 23. Aturan data diterima linear bila nilai $\mathrm{P}>0.05$. maka data dinyatakan linear, pengujian linearitas dengan menggunakan teknik Anova. Hasil uji prasyarat Linearitas model angka statistik dari menu Means disajikan pada Tabel 5. 
Tabel 5. Hasil Uji Normalitas Data

One-Sample Kolmogorov-Smirnov Test

\begin{tabular}{|c|c|c|c|c|}
\hline & & $\begin{array}{l}\text { X Metode Token Y } \\
\text { Economy }\end{array}$ & $\begin{array}{l}\text { Y Motivasi } \\
\text { Matematika }\end{array}$ & Belajar \\
\hline \multicolumn{2}{|l|}{$\mathrm{N}$} & 20 & 20 & \\
\hline \multirow{2}{*}{$\begin{array}{l}\text { Normal } \\
\text { Parameters }{ }^{\mathrm{a}, \mathrm{b}}\end{array}$} & Mean & 14.05 & 43.35 & \\
\hline & $\begin{array}{l}\text { Std. } \\
\text { Deviation }\end{array}$ & .999 & 2.852 & \\
\hline \multirow{3}{*}{$\begin{array}{l}\text { Most Extreme } \\
\text { Differences }\end{array}$} & Absolute & .230 & .281 & \\
\hline & Positive & .171 & .281 & \\
\hline & Negative & -.230 & -.251 & \\
\hline \multicolumn{2}{|c|}{ Kolmogorov-Smirnov Z } & 1.029 & 1.259 & \\
\hline \multicolumn{2}{|c|}{ Asymp. Sig. (2-tailed) } & .240 & .084 & \\
\hline
\end{tabular}

a. Test distribution is Normal.

b. Calculated from data.

Tabel 6. Hasil Uji Linearitas

\begin{tabular}{|c|c|c|c|c|c|c|c|}
\hline & & & $\begin{array}{l}\text { Sum of } \\
\text { Squares }\end{array}$ & df & $\begin{array}{l}\text { Mean } \\
\text { Square }\end{array}$ & $\mathrm{F}$ & Sig. \\
\hline \multirow{5}{*}{$\begin{array}{l}\text { Y Motivasi } \\
\text { Belajar } \\
\text { Matemati } \\
\text { ka * X } \\
\text { Metode } \\
\text { Token } \\
\text { Economy }\end{array}$} & \multirow{3}{*}{$\begin{array}{l}\text { Between } \\
\text { Groups }\end{array}$} & (Combined) & 98.008 & 3 & 32.669 & 9.245 & .001 \\
\hline & & Linearity & 74.803 & 1 & 74.803 & 21.168 & .000 \\
\hline & & $\begin{array}{l}\text { Deviation } \\
\text { from Linearity }\end{array}$ & 23.205 & 2 & 11.603 & 3.283 & .064 \\
\hline & \multicolumn{2}{|c|}{ Within Groups } & 56.542 & 16 & 3.534 & & \\
\hline & \multicolumn{2}{|l|}{ Total } & 154.550 & 19 & & & \\
\hline
\end{tabular}

Koefisien linearitas dilihat pada Deviation from Linearity, yaitu harga $F=3.283$ dan Sig. $=0.064$. Data skor kedua variabel diatas dinyatakan berhubungan secara linear. Hal ini ditunjukkan dengan nilai Sig. dalam Tabel 6 lebih besar dari 0.05. Dengan demikian, uji selanjutnya dapat dilakukan karena kedua data memiliki hubungan yang linear. 
Koefisien determinasi $\left(\mathrm{R}^{2}\right)$ bertujuan untuk mengetahui seberapa besar kemampuan variabel independen (metode token economy) mampu menjelaskan variabel dependen (motivasi belajar matematika). Berikut disajikan hasil uji determinasi $\left(\mathrm{R}^{2}\right)$, tabel 7.

\section{Tabel 7. Hasil Koefisien Determinasi}

\begin{tabular}{|c|c|c|c|c|}
\hline Model & $\mathrm{R}$ & R Square & Adjusted R Square & Std. Error of the Estimate \\
\hline 1 & $.696^{a}$ & .484 & .455 & 2.105 \\
\hline
\end{tabular}

Nilai $r$ dalam Tabel 7 adalah 0,696. Dengan nilai $r$ tidak terdapat tanda negatif berarti pengaruh metode token economy terhadap motivasi belajar matematika itu positif dan kuat.

Uji hipotesis menggunakan teknik uji regresi linier dengan tujuan untuk mengetahui seberapa besar tingkat pengaruh antara metode token economy terhadap motivasi belajar matematika. Kaidah pengujian yaitu dengan membandingkan nilai Sig dengan taraf signifikan $\alpha=0,05$. Jika nilai Sig $>\alpha$, maka $\mathrm{H}_{0}$ diterima. Dan jika nilai $\mathrm{Sig}<\alpha$, maka $\mathrm{H}_{0}$ ditolak. Diketahui yaitu nilai Sig. sebesar 0,001. Ternyata nilai $0,001<0,005$, maka $\mathrm{H}_{0}$ ditolak. Keputusan hasil output uji anova regresi linear menunjukkan model regresi linear dapat digunakan untuk memprediksi motivasi belajar matematika yang dipengaruhi oleh metode token economy.

Tabel 8. Hasil Uji Regresi Linear

\begin{tabular}{|c|c|c|c|c|c|c|}
\hline \multirow{2}{*}{\multicolumn{2}{|c|}{ Model }} & \multicolumn{2}{|c|}{$\begin{array}{l}\text { Unstandarized } \\
\text { Coefficients }\end{array}$} & \multirow{2}{*}{$\begin{array}{c}\text { Standarized } \\
\text { Coefficients } \\
\text { Beta } \\
\end{array}$} & \multirow[b]{2}{*}{$\mathrm{t}$} & \multirow[b]{2}{*}{ Sig. } \\
\hline & & $\mathrm{B}$ & Std. Error & & & \\
\hline \multirow[t]{2}{*}{1} & (Constant) & 15.435 & 6.810 & & 2.267 & .036 \\
\hline & X Metode Token Economy & 1.987 & .484 & .696 & 4.109 & .001 \\
\hline
\end{tabular}


Pada Tabel 8 ini dikemukakan nilai koefisien dari persamaan regresi. Dalam hal ini, persamaan regresi sederhana yang digunakan adalah :

$$
\mathbf{Y}=\mathbf{a}+\mathbf{b X}
$$

Di mana:

$\mathrm{Y}=$ Motivasi Belajar Matematika

$\mathrm{X}=$ Metode Token Economy

Dari hasil output diperoleh persamaan regresi:

$$
Y=15,435+1,987 X
$$

Koefisien-koefisien persamaan regresi linier sederhana diatas dapat diartikan koefisien regresi untuk konstan sebesar 15,435 menunjukkan bahwa jika variabel metode token economy bernilai nol atau tetap maka akan meningkatkan motivasi belajar matematika sebesar 15,435 satuan. Variabel metode token economy 1,987 menunjukkan bahwa jika variabel metode token economy meningkat 1 satuan maka akan meningkatkan motivasi belajar matematika sebesar 1,987. Jadi, setiap kenaikan atau penurunan skor sebesar 1 pada variabel metode token economy, akan menyebabkan naik atau turunnya motivasi belajar matematika sebesar 1,987 satuan.

Nilai t bilangan konstan adalah 2,267 dengan Sig. sebesar 0,036 dan metode token economy adalah 4,109 dengan Sig. sebesar 0,001 . Jadi nilai P keduanya adalah 0,036 dan 0,001 . Untuk menguji signifikansi atau kevalidan persamaan regresi dilakukan dengan menggunakan teknik probabilitas $(\alpha)$ yaitu dengan membandingkan nilai Sig. dengan $\alpha=0,05$. Jika nilai $\mathrm{P}<\alpha$ maka $\mathrm{H}_{0}$ ditolak dan $\mathrm{H}_{1}$ diterima. Berdasarkan kriteria di atas maka $\mathrm{H}_{0}$ ditolak dan $\mathrm{H}_{1}$ diterima. Berarti metode token economy berpengaruh positif dan 
signifikan terhadap motivasi belajar matematika peserta didik MI Ma'arif Giriloyo 2.

Berdasarkan uji hipotesis yang dilakukan melalui uji regresi diperoleh persamaan regresi $Y=15,435+1,987 X$. Hal ini menunjukkan bahwa setiap kenaikan skor sebesar 1 pada variabel metode token economy akan meningkatkan motivasi belajar matematika sebesar 1,987. Demikian juga sebaliknya, setiap penurunan sebesar 1 akan menurunkan motivasi belajar matematika sebesar 1,987. Sehingga setiap kenaikan atau penurunan skor sebesar 1 pada variabel metode token economy, akan menyebabkan naik atau turunnya skor motivasi belajar matematika sebesar 1,987 satuan. Nilai t bilangan konstan adalah 2,267 dengan Sig. 0,036 dan metode token economy sebesar 4,109 dengan Sig. 0,001. Sehingga P untuk keduanya 0,036 dan 0,001 .

Pengujian signifikansi menggunakan teknik probabilitas $(\alpha)$. Yaitu dengan membandingkan Sig. (P) dengan $\alpha . \mathrm{H}_{0}$ ditolak bila Sig $<\alpha$, dan $\mathrm{H}_{1}$ diterima. Hal ini menunjukkan bahwa metode token economy berpengaruh positif dan signifikan terhadap motivasi belajar matematika peserta didik kelas III B MI Ma'arif Giriloyo 2. Signifikan merupakan bagian dari hasil penelitian yang mewakili populasi. Karena, penelitian ini adalah penelitian populasi. Di mana semua sampel digunakan. Maka hasil dari uji hipotesis yaitu metode token economy berpengaruh terhadap motivasi belajar matematika peserta didik MI Ma'arif Giriloyo 2. Sedangkan koefisien determinasi $\left(\mathrm{R}^{2}\right)$ yaitu sumbangan yang diberikan metode token economy ini terhadap motivasi belajar yaitu sebesar 0,484 yang dapat dilihat dalam tabel Model Summary pada kolom $R$ square. 
Dengan hasil output dan analisis terhadap uji hipotesis teknik regresi linear sederhana menunjukkan bahwa metode token economy mempengaruhi motivasi belajar matematika peserta didik kelas III B MI Ma’arif Giriloyo 2.

\section{SIMPULAN}

Dari hasil penelitian diperoleh hasil uji regresi linear sederhana menunjukkan bahwa terdapat pengaruh positif antara penggunaan metode token economy terhadap motivasi belajar matematika. Hal ini ditunjukkan dengan nilai $\mathrm{P}$ sebesar 0,036 dan 0,001 atau $\mathrm{P}<0,05$. Artinya, $\mathrm{H}_{0}$ ditolak dan $\mathrm{H}_{1}$ diterima. Pengaruh positif ini menunjukkan nilai token economy meningkat maka motivasi belajar matematika meningkat. Metode token economy memiliki sumbangan pengaruh sebesar 0,484 atau 48,4 \% terhadap motivasi belajar matematika peserta didik. Adapun sisanya sebesar $51,6 \%$ disebabkan oleh faktor lain yang tidak disertakan dalam penelitian ini.

\section{E. DAFTAR PUSTAKA}

Heruman. Model Pembelajaran Matematika Di Sekolah Dasar. Bandung: PT. Remaja Rosdakarya, 2013.

Ibrahim, and Suparni. Pembelajaran Matematika Teori Dan Aplikasinya. Yogyakarta: Suka Press, 2012.

Kadir. Statistika Terapan: Konsep, Contoh Dan Analisis Data Dengan Program SPSS/Lisrel Dalam Penelitian. Jakarta: Rajawali Pers, 2016.

Latipah, Eva. Pengantar Psikologi Pendidikan. Yogyakarta: Insan Madani, 2012.

Malik, Oemar. Psikologi Belajar \& Mengajar. Bandung: Sinar Baru Algesindo, 2007.

Nurgiyantoro, Burhan, Gunawan, and Marzuki. Statistik Terapan. Yogyakarta: Gadjah Mada University Press, 2015. 
Purwanta, Edi. Modifikasi Perilaku. Yogyakarta: Pustaka Pelajar, 2015.

Purwanto, Ngalim. Psikologi Pendidikan. Bandung: PT. Remaja Rosdakarya, 2007.

Rohmah, Noer. Psikologi Pendidikan. Yogyakarta: TERAS, 2012.

Schunk, Dale H., Paul R. Pintrich, and Judith L. Meece. Motivasi Dalam Pendidikan : Teori, Penelitian Dan Aplikasi. Jakarta: Indeks, 2012.

Siregar, Sofyan. Statistika Terapan Untuk Perguruan Tinggi. Jakarta: Kencana, 2015.

Sugiyono. Statistika Untuk Penelitian. Bandung: Alfabeta, 2014.

Sukaji, Sutarlinah. Modifikasi Perilaku: Penerapan Sehari-Hari Dan Profesional. Yogyakarta: Liberty, 1983.

Uno, Hamzah B. Teori Motivasi \& Pengukurannya. Jakarta: Bumi Aksara, 2008. 